\title{
Assessment of Causal Relationships Between Motivational Climates, Goal Orientations and "Zest for Living" in Junior High School Physical Education Classes*
}

\author{
Takumi Nakasuga ${ }^{1}$, Shunsuke Sakata ${ }^{2}$, and Yoshio Sugiyama ${ }^{3}$ \\ ${ }^{1}$ Graduate School of Education, Hyogo University of Teacher Education, 942-1 Shimokume, Kato-shi, Hyogo 673-1494 \\ nakasuga@hyogo-u.ac.jp \\ ${ }^{2}$ Health and Sports Science Center, Kyushuu Sangyo University, 2-3-1 Matsukadai Higashi-ku, Fukuoka 813-8503 \\ ${ }^{3}$ Graduate School of Human-Environment Studies, Kyushu University, 6-1 Kasuga-koen, Kasuga-shi, Fukuoka 816-8580 \\ *Original article published in Japan J. Phys. Educ. Hlth. Sport Sci. 63: 623-639, 2018 (in Japanese)
}

\begin{abstract}
Causal relationships among perceived motivational climates in physical education classes, goal orientations, and "Zest for Living" (ZL) were investigated reciprocally in junior high school students. This longitudinal study involved 1045 junior high school students (mean age $=13.9+0.8$ years) who completed questionnaires on 5 occasions at 2 -month intervals throughout the academic year. The measures used included a questionnaire on motivational climates in physical education (mastery climate, cooperative climate, and performance climate), a scale assessing goal orientations (student task orientation and student ego orientation), and a scale assessing ZL. The validity of the 5-wave cross-lagged effect model was verified using structural equation modeling. The results of the study suggested the following processes: (1) The mastery climate and cooperative climate had positive causal effects on ZL. (2) The mastery climate and cooperative climate had positive causal effects on ZL through mediation of task orientation, and exhibited a positive cycle. (3) The performance cli mate had positive causal effects on ego orientation, but negative causal effects on task orientation. In conclusion, to enhance $Z \mathrm{~L}$ in junior high school students, it is important for teachers to cultivate a mastery climate and cooperation climate in physical education classes. In addition, the performance climate in physical education classes has an indirect negative impact on $\mathrm{ZL}$.
\end{abstract}

Keywords: mastery climate, cooperative climate, performance climate, physical education class in junior high school, longitudinal research

\section{Introduction}

In recent years, society has rapidly changed due to advances in computerization and globalization. Having a school education is essential to developing the ability to succeed in this rapidly changing environment. This ability to succeed - or Zest for Living (ZL) - is the fundamental philosophy behind Japanese education, as was set out in the 1996 Central Council for Education report, "The State of Education in Japan with an Outlook on the 21st Century" and is defined as, "The basic abilities and skills to discover, learn, consider, and judge issues independently and to act in order to solve problems in a better way; rich humanity in order to control oneself, collaborate with others, and think of others; and the health and physical strength to live vigorously." (Central Council for Education, 1966). Thereafter, basic policies as outlined in the New Curriculum Guidelines (revised in March 2017) also adhered to this philosophy of a ZL, and asked for the further development of children's ZL through various educational activities (e.g., problemsolving learning in each subject and experience learning in special activities) (Ministry of Education, Culture, Sports, Science and Technology, 2017). In this context, the development and examination of an effective school education that develops ZL has garnered significant attention. Studies that focus on developing ZL through class practice cover various 
school subjects including mathematics (Hayashi et al., 2016), social studies (Sasaki, 2005), home economics, and workshop classes (Furusawa et al., Yamaguchi, 2012), and health (Miyata et al., 2003). These studies focused on aspects of Zest of Living in relation to problem-solving abilities, thinking and decisionmaking abilities, and the maintenance and promotion of health and proposed teaching materials and practical examples to enhance these abilities. Studies on the nature-experience activities that were conducted by the sea or in the mountains resulted in the discovery of unique perspectives that identified ZL as being comprised of three abilities: psychological and social abilities (e.g., proactivity and decision-making), moral abilities (e.g., compassion and self-regulation), and physical abilities (e.g., tolerance and activity) (Tachibana et al., 2003). In addition, there have been reports that one's psychological and social abilities increase after undertaking nature activities, particularly in proactivity and decision-making (Aoki et al., 2005; Nakagawa et al., Tachibana et al., 2003). School sports club activities, which are considered extracurricular activities, also develop abilities such as communication, perseverance, and a sense of respecting societal norms fostered through adherence to rules and manners and through interacting with other schools. There have been reports that such abilities are associated with the development of healthy bodies, solid academic abilities (such as goal-setting and problem-solving), and spiritual enrichment (Nakagawa, Arai, 2006). As demonstrated here, research on ZL extends beyond the framework of subjects and learning experiences, and is actively conducted across various educational activities.

Amidst the diverse educational activities taught today, physical education, which aims to develop a healthy body and mind through mainly physical activities, is receiving particular attention as a subject that contributes to the development of ZL (Nishida et al., 2010; Nishijima et al., 2000; Sakairi, 2008). Physical education involves students attempting self-set goals and challenges, as well as activities to solve problems by exchanging opinions with their peers. This kind of education provides abundant scenarios in which these students, by undertaking these activities, can lead and engage with the subject first-hand by being physically active. The basic requirements of a physical education class can be said to serve as the basis for the development of the following abilities, which are part of the ZL: "The ability to learn, think and judge by oneself and to express oneself," "humanity and sociability, such as collaborating vigorously with others, and thinking of others," and "promotion of health and physical strength to live well and self-awareness of one's own physical capabilities." Recently, the mechanism by which physical education contributes to the development of ZL has been examined through practical and research studies. For example, long-jump in track and field (Okamoto et al., 2004), long-distance running (Watanabe \& Ueya 2003), basketball (Fusasaki et al., 2001), dance (Nakamura et al., 2001), as well as kendo and judo (Moriyama, 2011) have all been discussed through classroom practice. These studies found that measures such as the development of teaching materials aimed at simplifying sporting events, making adjustments to evaluation methods (e.g., self or mutual evaluation). Further, looking at the ways in which the children form goals brought about the following changes to the children after the completion of the subject unit: the development of the ability to learn and think independently and abilities to challenge and solve problems (Fusasaki et al., 2001; Nakamura et al., 2001; Okamoto et al., 2004) and the development of a mindset that values one's peers and a has positive attitude toward following rules (Moriyama, 2011; Watanabe \& Ueya, 2003). Thus, these studies were successful in qualitatively confirming (e.g., through the students' statements and learning records) that changes have occurred in terms of the ZL aspects, such as in the student's independent learning activities and a rich sense of humanity. Additionally, Nishida et al. (2010) developed a one-factor scale consisting of eleven items as a general measure of ZL within elementary school students (fifth and sixthgrade students) and junior high school students (seventh to ninth grade students) based on the definition of ZL mentioned at the beginning of this paper (e.g., the scale measured "identifying a task by oneself" with "I can find out what needs to be done by myself" and "learning by oneself" with "I voluntarily learn various things by myself"). Examining the correlation between ZL scores with various other variables' scores (e.g., learning motivation and stress adaptation in physical education class situations, and social skills) indicated that the learning motivation and social skills of students in physical education situations are strongly correlated with ZL. Furthermore, Nishijima et al. (2000) examined the process behind developing behavioral aspects of autonomously confronting issues out of a Zest of Living from the three 
factors of interest and motivation during physical education, satisfaction toward lessons, and self-efficacy. The results indicated that autonomous behaviors are influenced by interest and motivation during physical education, and thus, improved through a cyclical process that involves a sequence of satisfaction and efficacy. Therefore, it can be surmised that the development of ZL is closely linked with the instruction or evaluation of teachers involved in physical education and by the children's psychological factors. While many variables exist in physical education learning settings, a detailed examination of how these variables correlate with the development of ZL has not been conducted. These variables include the teachers' values regarding providing guidance (e.g., effort and performance), the evaluation criteria (absolute and relative assessment), the class orientation (whether the class prefers maintaining new records, enjoys competing, or emphasizes maintaining relationships with peers). These variables are related to different learning climates created by the teacher or classmates and each student's perception of their goals. Furthermore, the aforementioned study that examined ZL in physical education learning provides a practical example through its results obtained through a short-term intervention for a single class of approximately one month, or only examined cross-sectional data that collected the positive and negative relationships of the variable from a single period. Therefore, such studies are limited in that they have not reached the point of estimating a causal relationship based on continuous data collected over a long-term period that fully covers the changes in ZL over time.

Additionally, the field of motivational research concerning physical education learning includes the concept of achievement goal theory. This theory is said to be effective when examining teaching methods and evaluating teaching standards, the orientation of the class, and the differences in the group or individuals' goals (e.g., the difference in each individual student's goals) in a structured manner. This theory explains the difference between the motivational processes that differently impact the behavior, perception, and emotions of students depending on the type of goals they had adopted in the learning scene (e.g., performance goals that emphasize display of ability and comparison with others and mastery goals that emphasize the effort toward skill improvements) (Ames, 1992; Dweck, 1986; Ito, 1998; Nicholls, 1983; Nishida \& Ogata, 2008; Jobuchi, 2003). According to the theory, the type of achievement goal that motivates students is determined by the motivational climates, which is comprised of the goals of the student's surrounding (group) such as from the teachers or classmates, and goal orientation, which is the individual's own orientation toward goals (Ito et al., 2008; Ntoumanis \& Biddle, 1999). The motivational climate is said to be an environmental structure created by others that is important to a learning environment (e.g., teachers and classmates). It consists of two aspects: the performance climate, where ability is valued and achievement through competition is emphasized, and the mastery climate, where effort is valued and the process toward attainment of mastery is emphasized (Ames, 1992; Nishida \& Ogata, 2008; Roberts, 1992; Roberts \& Kristiansen, 2012). Thus, the motivational climate can be utilized as a conceptual base for examining environmental factors in physical education situations (Fujita \& Sugihara, 2007; Nakasuga et al., 2015, 2017). Furthermore, there is also the concept of a cooperative climate (a climate in which collaborative experiences with peers are valued, emphasizing the interaction between students more than skill acquisition and comparison with others (competition)). Recently, a novel perspective has surfaced attempting to perceive motivational climates using the characteristics of all three aspects, including the cooperative climate (Ito et al., 2013). "Goal orientation" refers to a concept that indicates the individual factors (or individual differences) in how a person perceives goals (Isogai, 2002; Ito, 2000). This concept can be divided into two categories: ego orientation, which emphasizes superiority or inferiority and results-based and comparison with others, and task orientation, which emphasizes improving one's skills through knowledge acquisition and the development of abilities (Sasaki, 2013).

In previous studies focusing on the difference between how students perceive their learning climate in physical education classes, as well as the orientation of what the students emphasize in these classes, the cognitive, emotional, and behavioral aspects of students, were treated as dependent variables. Using cross-sectional and longitudinal research procedures, studies have begun to examine the effects of and relationships between these variables. In such crosssectional studies, hypothesized models which set mastery and performance climates as independent variables, task/ego orientations as mediating variable, and normative behavior during physical education classes (Moreno et al., 2011), satisfaction (Nakasuga 
et al., 2017), intrinsic motivation (Ferrer Caja \& Weiss, 2000), and expectations toward sports activities (Nakasuga et al., 2015) as dependent variables were developed. Analysis of these models confirmed that there are both direct and indirect relationships between the variables. Additionally, in longitudinal studies, longitudinal data collected over a certain period of time from the same research participants were used. These data were used to examine causal relationships by using mastery and performance climates as independent variables, task/ego orientations as mediating variables, and enjoyment and boredom of physical education (Barkoukis et al., 2010; Grasten et al., 2012), assisting behavior (Kokkonen et al., 2013), and motivation to participate in sports outside of the class (Halvari et al., 2011; Jaakkola et al., 2012; Papaioanou et al., 2006) as dependent variables. These studies found that both mastery and performance climates impact task/ ego orientations, which, in turn, influence the noted dependent variables. From these results, it can be concluded that the effect of the education content will differ depending on how individual students perceive the climate of the group (e.g., teachers and classmates) as well as their personal orientation during physical education. Therefore, it can be predicted that the development of ZL (which is expected to occur through physical education) will be different depending on how students perceive the motivational climate and goal orientation.

However, previous studies have not examined the correlation between both motivational climate and goal orientation in physical education to $\mathrm{ZL}$, as well as the causal relationships that could be estimated between these three variables. Previous studies have also failed to examine continuous changes over time, which means that, at present, studies have not discussed the goals that groups and individuals have in physical education learning scenes. This has led to a further lack of discussion revolving around how such goals might contribute to the development of ZL. Similarly, studies have not sufficiently examined these factors to the point that they can provide valuable suggestions for establishing effective class climates or educational methods for groups and individuals.

The cross-lagged effect model has gained significant attention, mainly in the fields of personality (Takahira et al., 2006) and developmental psychology research (Nishida et al., 2014) as a method for estimating causal relationships based on research studies. It is also used to estimate causal relationships between ex- perience in athletic clubs and life skills in the field of physical education and sports psychology (Shimamoto \& Ishii, 2010). Most of the available Japanese studies focusing on motivational climates and goal orientation in physical education learning scenes (Hara \& Matsuda, 2008.; Ito et al., 2013; Nakasuga et al., $2014,2015,2017)$ have adopted a cross-sectional survey procedure to simultaneously measure each variable of independent, mediating, and dependent variables. However, this particular research method has a limitation of only being able to identify the positive or negative relationship between variables and their direction as a hypothesis (Shimamoto \& Ishii, 2010). Therefore, it is necessary to conduct a longitudinal study on motivational climate and goal orientation in physical education learning scenes and estimate the causal relationship between variables.

The most significant consideration when examining the causal relationship between variables using the longitudinal research procedure is ensuring that the condition of variable $\mathrm{X}$ precedes variable $\mathrm{Y}$ in time is met (Takahira et al., 2006). Given these conditions are met, the variables of motivational climate and goal orientation in the physical education class can be defined as variable $\mathrm{X}$ of the time precedence factor, and Zest for Life, which this study discusses, can be defined as variable $\mathrm{Y}$. The condition of temporal precedence can be satisfied by performing and examination using the aforementioned cross-lagged effect model. In addition, by increasing the number of measurement points from two to three points, or to more than three points, it is possible to introduce new constraints and paths into the model. This can enable the stable estimation of a causal relationship between variables (Finkel, 1995; Omi et al., 2005; Takahira, 2006). Specifically, the presence of a cyclical impact process within the relationship between variable $\mathrm{X}$ and variable Y (e.g., variable X1 (at the first measurement point) $\rightarrow$ variable Y2 (second measurement point) $\rightarrow$ variable X3 (third measurement point)) can be examined in a clear manner by utilizing panel data of three waves or more (Takahira et al., 2006).

Furthermore, with the cross-lagged effect model, the mediating effect of the causal relationship between two variables (e.g., variables $\mathrm{X}$ and $\mathrm{Y}$ ) with an additional variable (e.g., variable $\mathrm{Z}$ ) can be examined. For example, in this study, the model would make it feasible to study the mediating effect on the relationship between motivational climate and the educational content - which is a process that had been examined 
in past cross-sectional studies. Studies of the mediating effects of variables have the academic significance of obtaining in-depth findings related to human psychological processes (Takahira et al., 2006). Such studies also have the advantage of being able to estimate the causal effects between variables with higher accuracy by deconstructing the direct and indirect effects (Takahira et al., 2006).

Based on the existing research, this study aimed to examine the causal relationship between the three variables of the motivational climate, goal orientation, and ZL in physical education learning scenes by using a cross-lagged effect model. The model was based on the 5-wave panel data collected from five different points in a single year (from May 2015 to February 2016).

\section{Methods}

\subsection{Research participants and periods}

A continuous five-session questionnaire research (hereinafter, referred to as "Research 1-5") was conducted with 1,486 students enrolled in three junior high schools in Osaka prefecture. Of the 1,486 participants, 1,045 students (male: 547, female: 498, mean age: $13.9 \pm 0.8$ years old, effective response rate: $70.3 \%$ ) responded to all the questionnaires (i.e., Research 1-5) and did not have any missing data. These 1,045 participants were used for final analysis. The five sessions were conducted in May 2015 (Research 1), July 2015 (Research 2), October 2015 (Research 3), December 2015 (Research 4), and February 2016 (Research 5).

Regarding learning content in each survey period, track and field and apparatus gymnastics were mainly conducted during Research I, swimming during Research 2, dance and budo, alongside ball games during Research 3, track and field (in particular, long-distance and marathon running) during Research 4, and ball games (i.e., basketball and soccer) during Research 5 . These periods were determined by considering scheduling errors resulting from the start and end of long summer and winter vacations as well as school activities (e.g., various school events and supplementary classes). Therefore, although there was a deviation in data collection of about ten days between participating schools, the different research phases were mostly conducted every two months, starting from early May. After consultation with the on-site teachers, this two- month interval was determined independently so as to avoid burdening the students or interfering with the progress of class.

\section{Research content}

\subsection{Motivational climate}

The motivational climate measurement scale in physical education (Isogai et al., 2008) has had its factor structure reconstructed by Ito et al. (2013). In this study, the motivational climates perceived by students during physical education were measured using the scale developed by Ito et al. (2013). The instruction sentence was: "Please answer the following questions on your physical education class." The subscales of this measure is comprised of three factors consisting of six items each, to a total of 18 items: 1) mastery climate (e.g., "The teacher praises students who try or work hard, even if the records and results are poor."), 2) performance climate (e.g., "In physical education learning, it is important to see whether or not you can do better than others in sports"), and 3) cooperative climate (e.g., "In this class, we help each other to get better"). Participants were asked to make a self-evaluation using a 5-point scale ranging from "Very applicable" (5 points) to "Not at all applicable" (1 point). Both the reliability and validity of this scale have been confirmed in studies on elementary school students (Ito et al., 2013), but not for junior high school students. Therefore, the Cronbach's alpha was calculated, and additional confirmed factor analysis was conducted. As a result, sufficient reliability and validity that met the standard values were confirmed, and numerical values indicating satisfactory reliability and validity were obtained even in the data collected after Survey 2 (Table 1).

\subsection{Goal orientation}

For a scale to measure goal orientation, the goal orientation scale developed by Fujita (2009) was used. The instruction sentence was "Describe a time when you believed you succeeded (did well) in PE class" The subscale of this measure is comprised of two categories consisting of five items each, to a total of 10 items, namely 1) ego orientation that performs ability evaluation in relation to others (e.g., "A time when I felt that I was superior than everybody else"), and 2) task orientation that performs ability evaluation in 
Table 1 Basic statistics, alpha coefficient, factor load, and fitness index for each scale.

\begin{tabular}{|c|c|c|c|c|c|}
\hline & Research 1 & Research 2 & Research 3 & Research 4 & Research 5 \\
\hline & May 2015 & July 2015 & October 2015 & December 2015 & February 2016 \\
\hline & $\begin{array}{l}\text { Mean/SD/alpha } \\
\text { coefficient/Factor } \\
\text { load }\end{array}$ & $\begin{array}{l}\text { Mean/SD/alpha } \\
\text { coefficient/Factor } \\
\text { load }\end{array}$ & $\begin{array}{l}\text { Mean/SD/alpha } \\
\text { coefficient/Factor } \\
\text { load }\end{array}$ & $\begin{array}{l}\text { Mean/SD/alpha } \\
\text { coefficient/Factor } \\
\text { load }\end{array}$ & $\begin{array}{l}\text { Mean/SD/alpha } \\
\text { coefficient/Factor } \\
\text { load }\end{array}$ \\
\hline \multicolumn{6}{|l|}{ Motivational climate } \\
\hline Mastery climate & $3.88 / .69 / .84 / .62-.75$ & $3.78 / .76 / .87 / .67-.79$ & $3.82 / .76 / .88 / .70-.80$ & $3.81 / .82 / .90 / .73-.81$ & $3.78 / .76 / .89 / .70-.80$ \\
\hline Cooperative climate & $3.80 / .71 / .81 / .52-.70$ & $3.78 / .77 / .85 / .61-.74$ & $3.70 / .76 / .86 / .64-.73$ & $3.69 / .81 / .88 / .65-.77$ & $3.65 / .75 / .86 / .55-.78$ \\
\hline Performance climate & $2.27 / .72 / .75 / .41-.73$ & $2.36 / .81 / .81 .45-.78$ & $2.41 / .82 / .85 / .55-.79$ & $2.48 / .80 / .83 / .54-.79$ & $2.54 / .77 / .83 / .51-.81$ \\
\hline Fit index & $\begin{array}{l}\mathrm{GFI}=.93, \\
\mathrm{AGFI}=.91, \\
\mathrm{CFI}=.92, \\
\mathrm{RMSEA}=.06\end{array}$ & $\begin{array}{l}\mathrm{GFI}=.93, \\
\mathrm{AGFI}=.91, \\
\mathrm{CFI}=.93, \\
\mathrm{RMSEA}=.06\end{array}$ & $\begin{array}{l}\mathrm{GFI}=.91, \\
\mathrm{AGFI}=.89, \\
\mathrm{CFI}=.92, \\
\mathrm{RMSEA}=.07\end{array}$ & $\begin{array}{l}\mathrm{GFI}=.92, \\
\mathrm{AGFI}=.89, \\
\mathrm{CFI}=.93, \\
\mathrm{RMSEA}=.07\end{array}$ & $\begin{array}{l}\mathrm{GFI}=.91, \\
\mathrm{AGFI}=.91, \\
\mathrm{CFI}=.92, \\
\mathrm{RMSEA}=.07\end{array}$ \\
\hline \multicolumn{6}{|l|}{ Goal orientation } \\
\hline Task orientation & $3.94 / .76 / .85 / .64-.77$ & $3.90 / .83 / .88 / .74-.80$ & $3.87 / .82 / .89 / .71-.81$ & $3.93 / .83 / .89 / .75-.80$ & $3.91 / .80 / .90 / .75-.83$ \\
\hline Ego orientation & $2.90 / .84 / .85 / .60-.80$ & $2.94 / .90 / .88 / .68-.81$ & 2.87/.92/.89/.72-.84 & $2.95 / .95 / .90 / .73-.83$ & $2.92 / .93 / .90 / .71-.85$ \\
\hline Fit index & $\begin{array}{l}\mathrm{GFI}=.96, \\
\mathrm{AGFI}=.93, \\
\mathrm{CFI}=.96, \\
\mathrm{RMSEA}=.08\end{array}$ & $\begin{array}{l}\mathrm{GFI}=.95, \\
\mathrm{AGFI}=.92, \\
\mathrm{CFI}=.96, \\
\mathrm{RMSEA}=.08\end{array}$ & $\begin{array}{l}\mathrm{GFI}=.96, \\
\mathrm{AGFI}=.93, \\
\mathrm{CFI}=.97, \\
\mathrm{RMSEA}=.08\end{array}$ & $\begin{array}{l}\mathrm{GFI}=.96, \\
\mathrm{AGFI}=.93, \\
\mathrm{CFI}=.97, \\
\mathrm{RMSEA}=.07\end{array}$ & $\begin{array}{l}\mathrm{GFI}=.95, \\
\mathrm{AGFI}=.91, \\
\mathrm{CFI}=.96, \\
\mathrm{RMSEA}=.08\end{array}$ \\
\hline Zest for Living & $3.59 / .56 / .85 / .40-.72$ & $3.67 / .68 / .91 / .54-.80$ & $3.58 / .63 / .89 / .46-77$ & $3.67 / .65 / .89 / .48-.80$ & $3.64 / .61 / .88 / .46-.76$ \\
\hline Fit index & $\begin{array}{l}\mathrm{GFI}=.96, \\
\mathrm{AGFI}=.93, \\
\mathrm{CFI}=.94, \\
\mathrm{RMSEA}=.07\end{array}$ & $\begin{array}{l}\mathrm{GFI}=.95, \\
\mathrm{AGFI}=.92, \\
\mathrm{CFI}=.96, \\
\mathrm{RMSEA}=.08\end{array}$ & $\begin{array}{l}\mathrm{GFI}=.94, \\
\mathrm{AGFI}=.91, \\
\mathrm{CFI}=.94, \\
\mathrm{RMSEA}=.07\end{array}$ & $\begin{array}{l}\mathrm{GFI}=.95, \\
\mathrm{AGFI}=.92, \\
\mathrm{CFI}=.95, \\
\mathrm{RMSEA}=.08\end{array}$ & $\begin{array}{l}\mathrm{GFI}=.95, \\
\mathrm{AGFI}=.93, \\
\mathrm{CFI}=.95, \\
\text { RMSEA }=.07\end{array}$ \\
\hline
\end{tabular}

relation to oneself (e.g., "A time when I felt that I finally improved after practicing a lot"). Participants were asked to make a self-evaluation using a 5-point scale ranging from "Very applicable" (5 points) to "Not at all applicable" (1 point). Concerning the instrument's reliability and validity, numerical values that met the standard values were obtained from data collected from Research 1 to 5 as in the aforementioned scale (Table 1).

\subsection{ZL}

As a scale for measuring ZL, a scale that Nishida et al. (2010) developed based on the definition of ZL was used. The instruction sentence was "What are your thoughts in PE class?" This scale consists of 1 factor with a total of 11 items related to ZL, (e.g., "I can find what I need to do on my own."). Participants were asked to make a self-evaluation using a 5-point scale ranging from "Very applicable" (5 points) to
"Not at all applicable" (1 point), with higher points indicating higher ZL. Concerning reliability and validity, numerical values that meet the standard values were obtained from data collected from Research 1 to 5 as in the aforementioned scale (Table 1).

\subsection{Procedures and ethical consideration ${ }^{* 1}$}

Before commencing data collection, permission was sought from the school principals, and principal health and physical education subject teachers. They were also provided with details regarding the purpose of the study as well as content for the questionnaire to inform their decision. The study was conducted only after discussing and ensuring mutual understanding between school principals, teachers, and researchers that all participating schools could withdraw from the study at any time, even in the middle of the longitudinal investigation. All parties were also made aware that the study could be suspended or stopped so as to 
accommodate and prioritize school events, or in cases where unexpected events occurred. In addition, at each junior high school, longitudinal (one-year) research implementation plans and research content were discussed again with the relevant school principal and teachers. These discussions confirmed that this study would specialize in researching the climate and orientation of physical education classes and that the consent of students' parents or guardians was not necessary because the research did not require writing down personal information. The front page of the questionnaire clearly stipulated the following: 1) the questionnaire was not a test, 2) the questionnaire had no relation to school grades, 3) the personal research results of the questionnaire would be confidential, and 4) the research results would not be published except for research purposes. The questionnaires were distributed during physical education classes, and participants answered them anonymously. Questionnaires were then collected directly upon completion. In addition, the teacher in charge explained to the students, before they filled in the questionnaire, that the participation was not compulsory and that students could withdraw at any time during the study. Students were also informed that they would not be penalized, even if they discontinued their cooperation, and that they would be regarded as having consented to participate in the study after responding to all questionnaire items. Furthermore, to match data from multiple research sessions, the students were asked to voluntarily write down the least-required information, which were class and student ID numbers.

The questionnaire was not distributed to or collected from each participating junior high school by mail. Instead, the researchers personally visited each school for each session and the filled-in questionnaires were collected directly from either the school principal or health and physical education teacher. Before each subsequent questionnaire session, the researcher confirmed that there had been no issues, hindrances, or inconveniences with conducting the research by asking the respective school principals and health and physical education teachers about the state of students during questionnaires as well as the current state of the physical education classes. The questionnaires were only distributed after establishing that the research could be continued and after informing the cooperating school that they could withdraw from the study at any time. Although schools were informed of their right to withdraw before each study phase, none of the cooperating schools requested to do so.

\subsection{Statistical analysis}

The cross-lagged effect model was verified by using structural equation modeling. Each fit index was used as the basis for selection of the model, including goodness of fit index (GFI), adjusted goodness of fit index (AGFI), comparative fit index (CFI), and root mean square error of approximation (RMSEA). The criteria for these indexes followed after those of Toyota et al. (1992) and Murohashi (2003): the GFI and CFI were set as 0.90 or higher, RMSEA as 1.00 or less, and the difference between the AGFI and GFI to be small. Similar criteria were used for the growth curve model analysis and confirmed factor analysis. The analysis was conducted using IBM SPSS Statistics 22.0 and IBM SPSS Amos 22.0 statistical packages, with a statistical significance level of $5 \%$.

\subsection{Analysis model}

A 5-wave cross-lagged effect model was adopted as the analytical model (Figure 1). The names of the observed variables in the model correspond to the scores of each subscale collected in this study. In the aforementioned motivational climates research in physical education centered on cross-sectional research (see Ferrer Caja \& Weiss, 2000; Moreno et al., 2011; Nakasuga et al., 2015, 2017), the perception of the motivational climate (independent variable) stipulates each students' task or ego orientation (mediating factor). Thus, these studies present a model of how students hold their task or ego orientations (mediating factor) and how these orientations impact different developed education content (dependent variable). Based on the perspectives of preceding studies, the following cyclical path was inferred, even in a longitudinal study, with the motivational climate as a starting point: the motivational climate is the independent variable (Research 1), goal orientation is the intermediate variable (Research 2), and the ZL (Research 3), goal orientation (Survey 4), and motivational climates (Survey 5) are the dependent variables.

The intersecting path created within this model estimates a causal relationship. For example, as shown in Figure 1, when Path $A$ has a significantly positive value, it signifies that mastery climate in physical education increases task orientation. Similarly, when Path $\mathrm{B}$ has a significantly positive value, it estimates that 


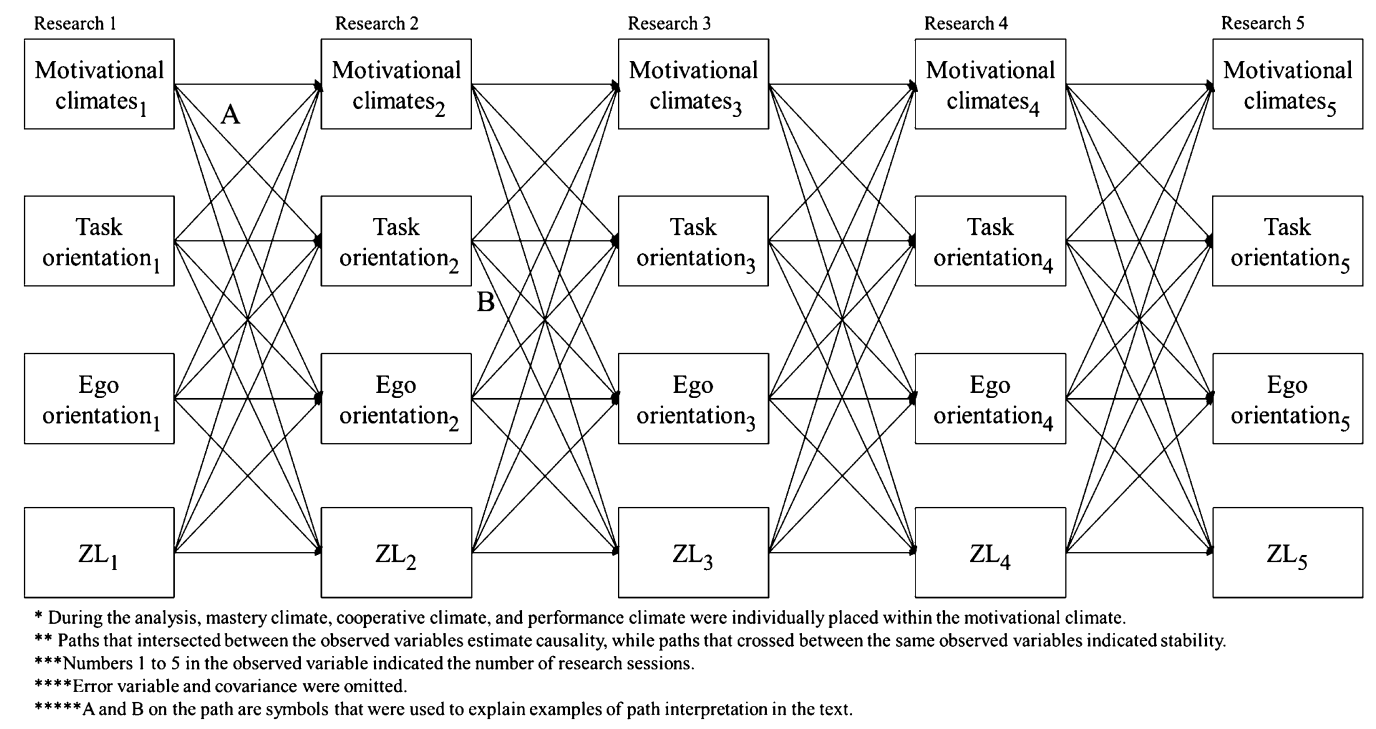

Figure 1 Analytical Model that Applies the Cross-Lagged Effect Model

the causal relationship of task orientation leads to the development of the ZL. If neither cross-delay effect is significant, the results were interpreted as having no causal relationship between the variables.

\section{Results}

\subsection{Basic statistics of each scale}

Table 1 presents the mean value, standard deviation, the Cronbach's alpha coefficient, and the fitness index of each scale score for all time points. To confirm temporal changes in ZL prior to conducting an analysis, a growth curve model was composed by having the ZL score from Research 1-5 as observed variables. The intercepts and slopes for the model were then accordingly estimated. As a result, the intercept was found to be $39.71(p<.05)$ and the slope was $.41(p<.05)$, indicating sufficient goodness of fit $(\mathrm{CFI}=.94, \mathrm{RMSEA}=.08)$. Since the positive slope was significant in the ZL score, it was concluded that ZL had a tendency to rise during physical education learning for the one-year period between Research 1 to Research 5.

\subsection{Model validation results}

\subsubsection{Model fit indices}

In this study, a cross-lagged effect model that focused on the three variables of motivational climate, goal orientation, and $\mathrm{ZL}$, was used to validate the causal relationship between the variables. The fit indi- ces of each model were GFI $=.92$ to .93 and $\mathrm{CFI}=.92$ to .93 , indicating a value over .90 for all models. The AGFI was also between .86-.87; not decreasing significantly in comparison to GFI. Furthermore, the RMSEA also showed values between .08 and 1.00 (Figures 2, 3, and 4). This indicates that the analytical model in this study was valid and can be used as an effective model for interpreting the causal relationship between each variable.

\subsubsection{Mastery climate, task/ego orientation, and $\mathrm{ZL}$}

The significant path coefficients found between mastery climate, task/ego orientation, and ZL are shown in Figure 2. Mastery climate positively affected task orientation $(\beta=.17, .06, .08, .18$ in order of the research period) and ZL $(\beta=.10, .07, .09-$ in that order, excluding Research 2-3). Task orientation positively affected mastery climate $(\beta=.06, .08-$ between Research 2-3 and 3-4) and ZL $(\beta=.15, .14$, $.12, .12$, in order of the research period) and negatively affected ego orientation $(\beta=-.10-$ only between Research 2-3). Ego orientation negatively affected mastery climate $(\beta=-.06,-.06-$ between Research 1-2 and 3-4) and task orientation $(\beta=-.07$, -.06 - between Research 3-4 and 4-5). ZL positively affected task orientation $(\beta=.11, .12, .16,-$ in that order, excluding Research 4-5). The path (stability) between these variables was as follows: mastery climate, $\beta=.57-.68$, task orientation, $\beta=.42-.47$, ego orientation, $\beta=.52-.57$, and $\mathrm{ZL}, \beta=.35-.43$. 


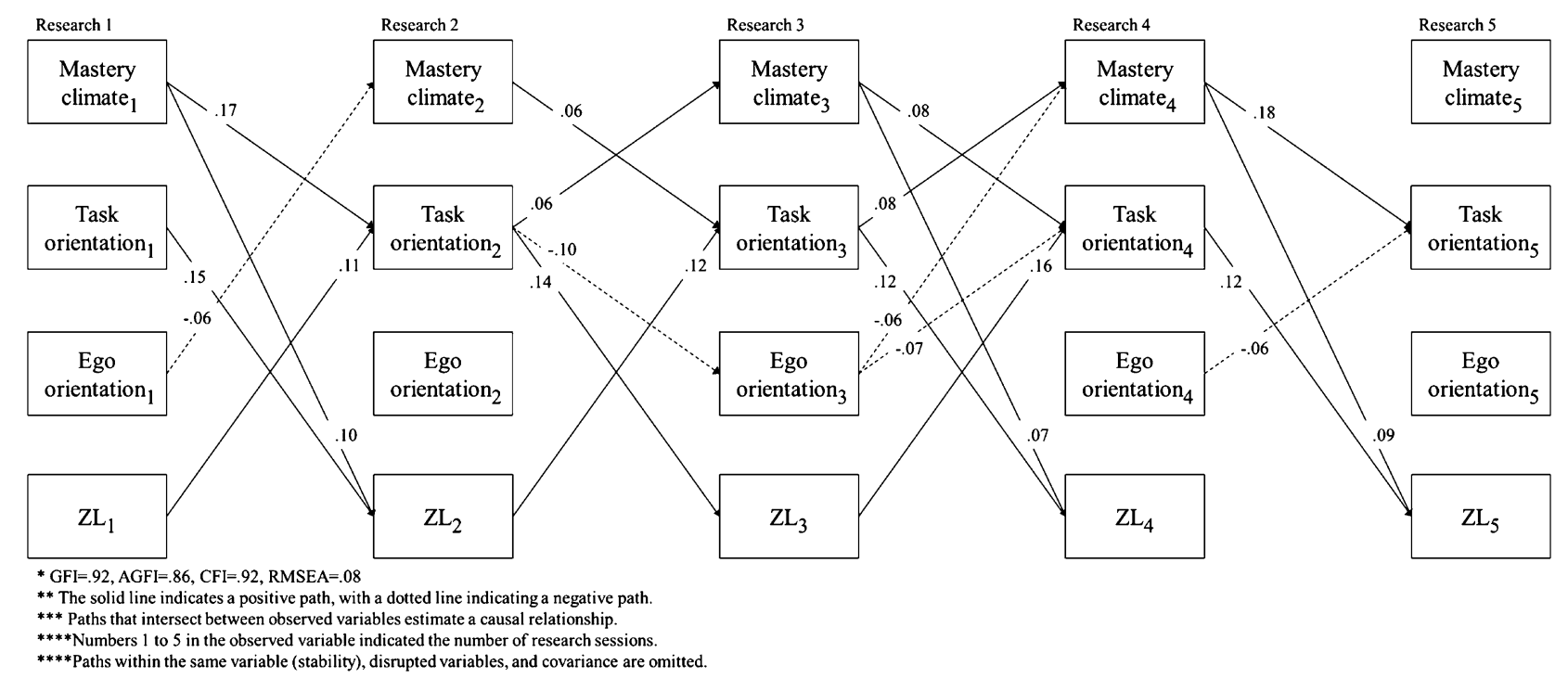

Figure 2 Relationship between mastery climate, task/ego orientation, and ZL

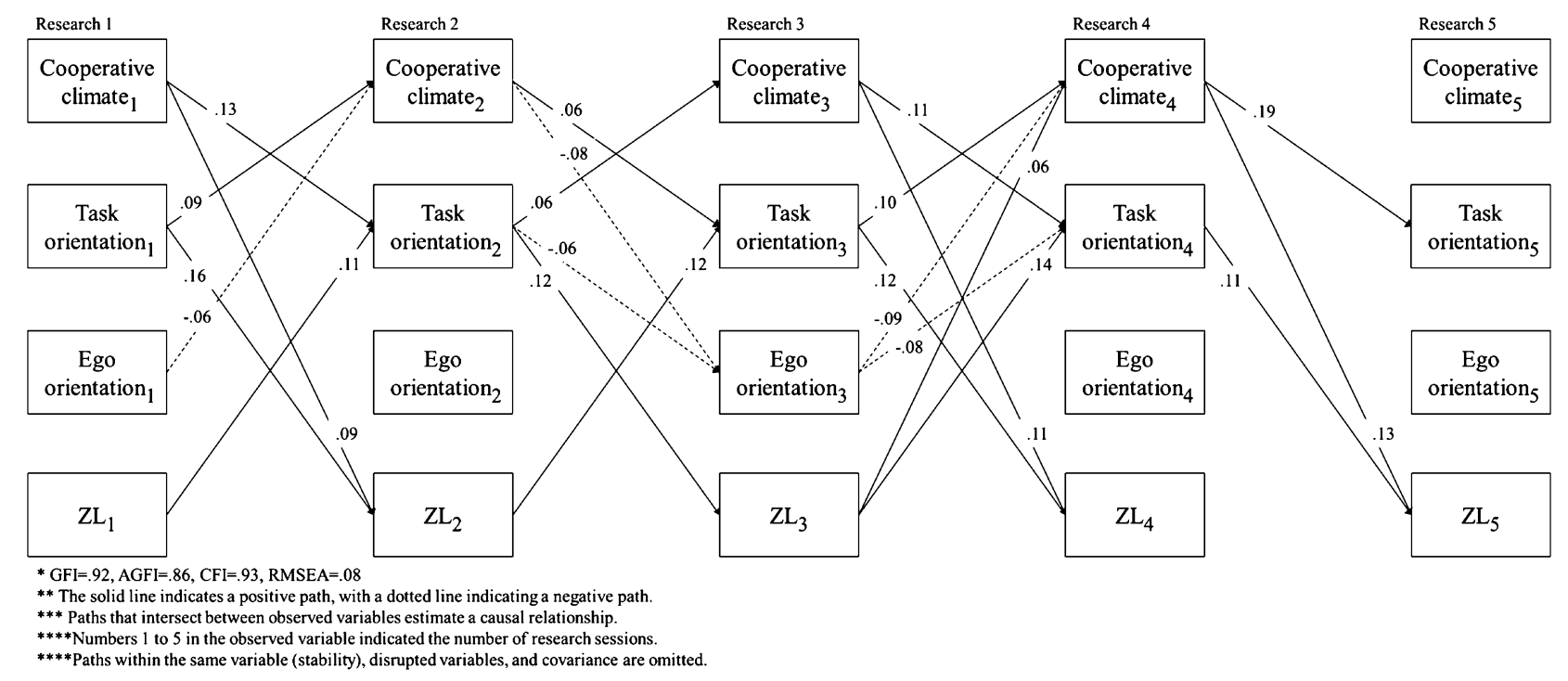

Figure 3 Relationship between cooperative climate, task/ego orientation, and ZL

\subsubsection{Cooperative climate, task/ego orientation, and $Z \mathbf{L}$}

The significant path coefficients found between cooperative climate, task/ego orientation, and ZL are shown in Figure 3. It was determined that cooperative climates positively affected task orientation $(\beta=.13$, $.06, .11$, and .19 , in the order of the research period) and ZL $(\beta=.09, .11, .13$, respectively-in that order, excluding Research 2-3), and negatively affected ego orientation $(\beta=-.08$ for Research 2-3). Task orientation positively affected cooperative climate $(\beta=.09$, $.06, .10$, in that order, excluding Research $4-5)$ and $\mathrm{ZL}$ $(\beta=.16, .12, .12$, and .11 , in order of the research period), and negatively affected ego orientation $(\beta=$
-.06 between Research 2-3). Ego orientation negatively affected cooperative climate $(\beta=-.06,-.09$ between Research 1-2 and 3-4) and task orientation $(\beta=$ -.08 between Research 3-4). ZL positively affected cooperative climate $(\beta=.06$ between Research 3-4) and task orientation $(\beta=.11, .12, .14$, in that order, excluding Research 4-5). The path (stability) between these variables was as follows: cooperative climate, $\beta=.55-.63$, task orientation, $\beta=.42-.47$, ego orientation, $\beta=.49-.50$, and $\mathrm{ZL}, \beta=.35-.41$.

\subsubsection{Performance climate, task/ego orientation, and $\mathbf{Z L}$}

The significant path coefficients found between 


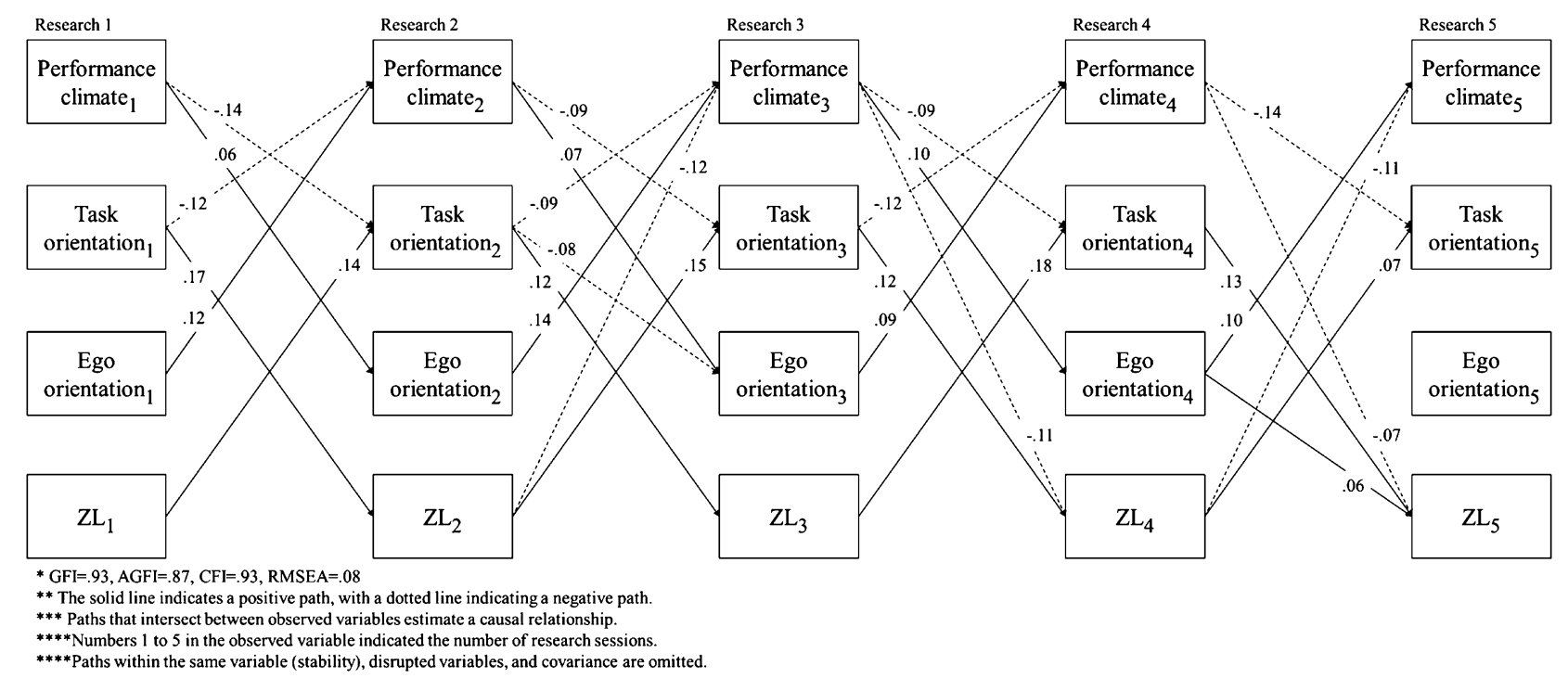

Figure 4 Relationship between performance climate, task/ego orientation, and ZL

performance climate, task/ego orientation, and ZL are shown in Figure 4. It was found that performance climate negatively affected task orientation $(\beta=-.14$, $-.09,-.09,-.14$, in the order of the research period) and ZL $(\beta=-.11,-.07$ between Research $3-4$ and $4-5)$, and positively affected ego orientation $(\beta=.06$, $.07, .10$, in that order, excluding Research 4-5). Task orientation negatively affected performance climate $(\beta=-.12,-.09,-.12$, respectively-in that order, excluding Research 4-5) and ego orientation $(\beta=-.08$ between Research 2-3), and positively affected ZL $(\beta=.17, .12, .12, .13$, in order of the research period). Ego orientation positively affected performance climate $(\beta=.12, .14, .09, .10$, in order of the research period) and ZL $(\beta=.06$ between Research 4-5). ZL negatively affected performance climate $(\beta=-.12$, -.11 between Research 2-3 and 4-5) and positively affected task orientation $(\beta=.14, .15, .18, .07$, in order of the research period). The path (stability) between these variables was as follows: performance climate, $\beta=.48-.56$, task orientation, $\beta=.43-.47$, ego orientation, $\beta=.48-.49$, and $\mathrm{ZL}, \beta=.36-.45$.

\subsubsection{Causal relationship to $\mathrm{ZL}$ with motivational climate as the starting point}

The direct effect of having students perceive the learning climate of both mastery and cooperative climates was found to improve ZL. Furthermore, an indirect effect was found in which the perception of both the mastery and cooperative climates strengthened students' task orientation. This heightened task orientation, in turn, positively impacted students' ZL.
In addition, a cyclical relationship was found in which the heightened ZL strengthened task orientation, which further strengthened the perception of both the mastery and cooperative climates. Conversely, a cyclical relationship was also found between climate and orientation whereby students' strong perception of the performance climate would strengthen their ego orientation. This strengthening of students' ego orientation, in turn, led them to like their performance climates. However, students who strongly perceived the performance climate had the possibility of their task orientation weakening. As mentioned before, task orientation has an effect of improving ZL, which made students perceive performance climate, lowering their task orientation. This is suggested to indirectly inhibit the increase of students' ZL. Although the existence of a path indicating that ego orientation increases $\mathrm{ZL}$ was found, this path consisted of lower values compared to other path values. As such, ego orientation's influence can be determined as being that strong. Based on the presented information, it was confirmed that the casual relationship between motivational climate, goal orientation, and ZL in physical education exhibits various formats. For example, depending on the perception of various climates (i.e., mastery, cooperation, and performance climates) and individual goals (e.g., task versus ego orientation), a cyclical relationship that includes direct and indirect effects between the variables were found, or that such a relationship was absent. 


\section{Discussion}

In this study, the causal relationship between motivational climate, goal orientation, and ZL in physical education learning scene was analyzed using a crosslagged effect model, based on 5-wave panel data collected throughout one year. The analysis showed that each fit index, which serves as an evaluation criterion of a model's overall validity, satisfied the standard value, indicating a good fit. Therefore, this model was deemed effective and applicable as a model for interpreting the causal relationship between the three variables of motivational climate, goal orientation, and ZL in physical education. Concerning each path, a cyclic and positive causal relationship that mainly included direct and indirect effects between mastery/cooperative climates, task orientation, and ZL was found. Conversely, the performance climate showed a negative causal relationship between task orientation and ZL, and a positive causal relationship with ego orientation, respectively. Based on these results, this section discusses 1) the causal relationship between mastery/ cooperative climates, task orientation, and ZL; 2) the causal relationship between performance climate, task/ ego orientation, and ZL; 3) the interval within the research study; 4) the error variable between the data collection periods; and 5) suggestions for classroom application.

\subsection{The causal relationship between mastery/coop- erative climates, task orientation, and $\mathrm{ZL}$}

A series of causal changes in the formation of $\mathrm{ZL}$, with the motivational climates in physical education as the starting point, demonstrated that students who perceive their mastery and cooperative climates (Research 1) start to hold problem-oriented goals toward success (Research 2). These goals, in turn, influence the formation of students' ZL (Research 3). Therefore, it was suggested that students' ZL heightens their task orientation (Research 4), further improving their ZL (Research 5) (Figures 2 and 3). In addition, a cyclicality was presented, in which the perception of the mastery/cooperative climates (Research 1) contributed to the formation of ZL (Research 2), increased task orientation (Research 3), and further increased the mastery and cooperative climates (Research 4). Such increases, as a whole, led to the improvement of ZL (Research 5) (Figures 2 and 3). Through these findings, this study confirmed that mastery and coopera- tive climates lead to the acquisition of $\mathrm{ZL}$, respectively. It was found that by having task orientation mediate these climates, a cyclical causal relationship between the variables is generated. In mastery climates, comprising of items such as "the teacher becomes very happy when I get better through practice or improve my records" or "the teacher praises those who work hard and make efforts, even if their records and results are poor," teachers pay attention to what kinds of procedures students go through until they become proficient. Teachers also place importance on such students' attitude as tackling slightly challenging tasks, as well as the attitude of making efforts even if the students ultimately fail. In cooperative climates, that consist of items such as "in this class, we help each other so that everyone can get better" and "in this class if there are people who cannot perform well in an exercise/sports, we think together about ways to help them," significance is placed on students helping each other and encouraging one another. In a physical education learning environment that emphasizes both a mastery or a cooperative climate, the rich support and assistance from teachers or students can be expected. In such environments, class engagement is praised, as opposed to solely focusing on improving students' skills. Failures that occur during activities (e.g., training and sports matches) are considered to be a source of growth for individuals and groups, forming part of the learning content in which students work together to solve problems. As a result, a cooperative climate does not include factors that promote anxiety (e.g., toward taking up new challenges and outcome) or make one feel denied. It is suggested that the students who recognize mastery and cooperative climates place the standard of goal achievement (success) on task orientation, which denotes selfreferential ability evaluations, such as "I am successful when I feel that I have finally improved after a lot of practice" and "I am successful when I become able to perform a task after trying hard." Among the students, there were those who were able to push their own abilities to the maximum, and those who felt growth through boldly challenging themselves, even after repeated failures. Thus, it is surmised that a cyclical flow exists, whereby improving students' abilities to identify tasks, think, act, and practice their empathy so as to build good human relationships, students may not be fearful or intimidated by challenges and failures, ultimately forming better ZL.

The study's results suggest that it is important to 
create a learning climate that encourages students to recognize mastery and cooperative climates, and to set tasks that make students' reasons for achieving their goals to be task-oriented. In this way, teachers and other stakeholders could assist students in ultimately enhancing their ZL in physical education throughout a given school year. Furthermore, the results of this study indicate that the various formats of causality exist between the studied variables.

\subsection{The causal relationship between performance climate, task/ego orientation, and $\mathrm{ZL}$}

This study's results suggested that the performance climate variable would lower the ZL and task orientation variables. In the performance climate, which consists of items such as "the teacher only cares about the record and the result" and "in physical education classes, whether you are better in sports than others is considered to be important," the outcome and results (e.g., whether students can perform an exercise, produce new records, or present with a win/loss) during the class is valued by both the teachers and the students. Students who lose in a game, fail a challenge or fail to improve on or set a new record in a physical education learning context that emphasizes a performance climate would see themselves as having poor abilities. If students cannot produce some form of welcome outcome in such a climate, they would be informing all those in the surroundings of their poor abilities. In addition, there is the possibility that such intense focus on performance could induce anxiety in students toward challenging sports or exercises, where the emphasis of winning and losing could lead to students harboring hatred toward their peers. These factors seem to hinder learning activities that emphasize students' autonomy, such as identifying tasks, learning, thinking, and acting independently, and are unsuitable for creating good teamwork.

In addition, a causal relationship was confirmed in which ego orientation tends to improve when the perception of performance climate is strengthened, while task orientation lowers. As comprised of items such as "when I felt that I was better than anyone else," and "when I played a more active role and stood out more than others," students with high ego orientation preferred an others-referential ability evaluation. In a performance climate that focuses predominantly on a student's ability to perform (or not perform) a sport well, and where improving records and winning or losing are valued, the standard of goal-setting (success) that students have is that if they outperform others or win, then they are successful. Since students in this kind of climate are interested in their position, as viewed from their surroundings through relative evaluation, they are believed to not be able to see the value in absolute evaluation. When the fundamental difference of whether the viewpoint of the ability evaluation is relative or absolute was compared and matched with the goals sought after in a performance climate, the coinciding ego orientation was improved. However, task orientation was believed to decrease, since the goal of the group did not coincide with the goal of the individual.

Finally, the causal relationship of task orientation decreasing performance climate and ego orientation improving performance climate is discussed (Figure 4). As mentioned previously, the perception of a mastery/cooperative climate is closely related to the factor behind the task orientation increased, and students with heightened task orientation strongly sought both mastery and cooperative climates in their next physical education learning. However, it is believed that students cannot find the need in performance climate, where they themselves may not be evaluated positively. Conversely, physical education classes that promote a performance climate can become places where students with high ego orientation, whose primary goal is to obtain a positive evaluation in a relative manner, are the only ones standing out and attracting attention. For this reason, such students are believed to perceive performance-climate classes as being necessary for learning climates. However, although strengthening ego orientation barely contributes to the development of $\mathrm{ZL}$, task orientation is an important factor for improving ZL, as mentioned previously. Therefore, practicing physical education that emphasizes a performance climate (which lowers task orientation), needs to be conducted carefully. It is noteworthy that the results of a cross-sectional study by Nakasuga et al. $(2014,2017)$ suggested that performance climate may be associated with a certain level of risk, but that it does not necessarily hinder learning. In this regard, this study also found a weak but positive causal relationship with ZL after observing a cyclical relationship between performance climate and ego orientation across Research 1 to Research 4, indicating improvement of both climates. As such, a result that is believed to support Nakasuga et al.'s (2014, 2017) suggestion was found. Considering that this 
study did not clarify the different relationships that exist between the factors comprising ZL and performance climate and/or ego orientation, such relationships need to be further examined in the future.

\subsection{Intervals within the research}

So far, an appropriate interval for conducting a longitudinal survey of the motivational climate, goal orientation, and ZL in the physical education learning scene has not been clarified. Concerning this matter, in this study, we conducted a 5-wave panel survey with an interval of approximately two months, taking into consideration students' burdens and the impact the study might have on class progression. The chosen interval was further based on discussions with the participating schools' officials. As a result, several significant cross-delay effects were found that could estimate the causal relationship between motivational climate, goal orientation, and ZL. The students' growth process through the year was also believed to have been sufficiently captured. However, the value of the effect that signified the strength of the causal relationship was, at most, $\beta \beta=.19$, which meant that this study cannot make any clear suggestions regarding how the length of the interval affected the size of the cross-delay effect. A task for future researchers would be to conduct a similar longitudinal investigation and collect findings on what might be an appropriate interval.

In psychology and education-related research (Akasaka \& Sakamoto, 2008; Omi et al., 2005; Kadoya, 2005; Yoshitake, 2010) that used a longitudinal approach with junior high school students as participants, the interval between the set research periods varied depending on the content and phenomena discussed. For example, there were studies that uniformly set the interval period between approximately 2-3 months, while others consisted of irregular intervals by centering on the educational sites. There is a possibility that if the period between the initial and follow-up research is longer than the period in which the causal relationship should be found, the relationship's impact will not be found (Okabayashi et al., 1998). Therefore, the setting of the research period may need to be considered carefully by placing priority on the research objectives. It is also more desirable to align the time points than to set the intervals irregularly (Takahira et al., 2006). However, longitudinal studies whose study subjects are school sites (e.g., elementary and junior high schools) should be conducted by giving priority to school events and class progression. Therefore, cases, where it is difficult to strictly align the duration between intervals, could be considered a limitation of longitudinal studies.

In the future, it is necessary to find the optimum interval period while observing any changes in the value of the cross-delay effect.

\subsection{Error variables within the data collection period}

Although this study was conducted during a single year, the impact of other factors, such as error variables, should also be considered when examining the relationship between measured variables. For instance, we investigated the causal relationship between motivational climate, goal orientation, and ZL in physical education classes. However, during a research period of one year, students have various experiences, such as attending other subjects' classes and school events, interacting with friends both inside and outside the school, and participating in school club activities. This is to say that physical education class experiences, solely, cannot be said to necessarily be the factor that impacts the fluctuation of students' ZL. Therefore, it is necessary to understand that conditions related to students that can serve as error variables (e.g., other classes and school events) are difficult to regulate when conducting a study whose subjects include both physical education classes and school education sites, and which aims to investigate social variables. Based on these noted points, ZL is developed through the complex interaction of various factors that students experience in their school and daily lives. Thus, physical education classes, alone, are not excellent indicators of the effect on the development of ZL. This study focused solely on physical education as a class subject to develop ZL, and merely found that the ways of perceiving a group's motivation and students' orientation, in particular, are important. Thus, it is necessary to remember that this study presented an outcome related purely to the physical education class, which is only a portion of the overall school education context.

\subsection{Suggestion for class practice}

As described at the beginning of this study, physical education is a subject expected to develop the children's ZL. In this study, the causal relationship be- 
tween motivational climate, goal orientation, and ZL in physical education was examined based on a model using a one-year longitudinal survey. The study results clarified that different impacts on ZL were caused by different physical education learning climates as well as the ways in which each student perceived their goals. In this section, based on the results gained from the study's model, practical suggestions are made regarding which state of physical education best promotes $\mathrm{ZL}$, as originating from the motivational climate.

For example, when a motivational climate is used as a starting point, and the formation of $\mathrm{ZL}$ is used as a final variable, multiple cyclic relationships can be confirmed, such as "mastery/cooperative climate (Research 1) $\rightarrow$ task orientation (Research 2) $\rightarrow$ ZL (Research 3) $\rightarrow$ task orientation (Research 4) $\rightarrow$ ZL (Research 5)" and "mastery/cooperative climate (Research 1) $\rightarrow$ ZL (Research 2) $\rightarrow$ task orientation (Research 3) $\rightarrow$ mastery/cooperative climate (Research $4) \rightarrow$ ZL (Research 5)". From these relationships, the following two points can be raised as significant aspects for developing students' ZL through physical education for one year: for teachers and students 1) to perceive both mastery and cooperative climates, and 2) to heighten students' task orientation.

According to Ames (1992), the conditions for emphasizing a mastery climate include setting short-term goals, providing opportunities for students to make an effort, and preparing challenging tasks. To meet these requirements, it is important for teachers to prepare multiple diverse and challenging tasks, and to encourage each student to select his or her own tasks by having students match their own skills with the tasks' levels of difficulty. Thereafter, it is necessary to offer sufficient opportunity (time) for each student to make an effort to complete the task, as well as to make each student understand that the effort (i.e., the effort the students put in and the practice they did) employed is what led to the problem's solution. In the cooperative climate, which is formed around students, it is necessary for teachers to not only have students pay attention to their own individual efforts, but also to have them acknowledge their peers' efforts and hard work and to check if they are helping one another. After establishing such an understanding, it is necessary to have students engage in team and group activities.

Conversely, the conditions for creating performance climates that have a negative impact on the $\mathrm{ZL}$ in physical education include: 1) providing students with uniform tasks determined in advance by teachers; 2) offering learning in a fixed group based on ability; and 3) giving the same tasks and exercise hours to all students, regardless of differences in students' skills (Ames, 1992). It is suggested that such performance climates hold the possibility of weakening students' task orientation, which is a key growth factor for ZL. As such, it is necessary to keep learning in a performance climate to a minimum when aiming to develop students' ZL through physical education. However, in terms of orientation, it is not necessary to weaken students' ego orientation, as it does not have an effect on their ZL. This is because the motivation of students may not be maintained if they are denied the opportunity to practice their preference for competition or comparison with others. Rather, it can be said that teachers need to focus more on improving task orientation than on limiting ego orientation.

Based on the presented results, the following educational suggestions are given: firstly, it is important for learning groups to incorporate both mastery and cooperative climates in order to create a climate of physical education learning that raises students' ZL throughout the year. Secondly, such an environment could increase each student's task orientation, which could then further increase their ZL.

\section{Tasks for the future}

Lastly, we provide a discussion of the major tasks for this study in the future.

Firstly, the results of this study were obtained from 5-wave panel data collected throughout a single school year. As such, it is not possible to understand, using this data, the changes that may occur during all three years of junior high school. For example, this study's findings would not assist in elucidating what ZL during the seventh grade might look like three years later, or how much physical education contributed to the development of ZL as a background factor. In the future, variables both related to $\mathrm{ZL}$ and other than $\mathrm{ZL}$ should be explored, such as learning motivation (Nishida \& Nishida 1990) and physical competence (Okazawa et al., 1996), both of which are said to show a remarkable decline in the three years of junior school). To establish such necessary findings, researchers would need to conduct a study over a long-term research period (i.e., three years - from admission to graduation) so as to clarify the relationship between these variables and motivational climate and/or goal 
orientation, and the specific process that occurs during physical education learning that is behind the transitions (i.e., improvements or declines) that may occur over time.

Secondly, the participants in this study consisted of junior high school students. However, in future, the scope of participants should be expanded to involve elementary school students (especially for those in the higher (fifth and sixth) grades) and high school students, and clarify the characteristics of each school type. Through these measures, we can better comprehend the effective learning climate, depending on the developmental stage, thereby, propose a learning design that takes into consideration the connection between school types.

Finally, it will be important to conduct an intervention study that collates the model obtained in this study, which displays the cyclic relationship of each variable, with the practical setting. Specifically, by developing physical education lessons with the intention of forming appropriate motivational climates, it may become possible to better confirm the development of students' ZL (as shown in this study) through additional qualitative data (e.g., statements and behaviors of students) to quantitative findings that can be obtained from scales.

In conclusion, future research is necessary to examine the motivational climates present in physical education learning contexts by conducting longer-term longitudinal research, expanding the research subjects, and incorporating perspectives of applying the findings into practical intervention.

\section{Acknowledgement}

We received the cooperation of many teachers and a multitude of students from junior high schools in order to conduct this yearlong study. We would also like to extend our warmest gratitude to the reviewers who shared their valuable opinions with us.

\section{Additional note}

This research was funded by the Grant-in-Aid for JSPS Research Fellow (15K 2 1548).

\section{Note}

*1 Although this research did not receive an ethics review from a research institute, this research was able to be carried out by giving sufficient consideration to the research content and implementation method with the cooperation of teachers and students. In the future, it will be important for research to be conducted by having researchers re-recognize research activities conducted through the lens of ethical considerations and reviews.

\section{References}

Akasaka, R. and Sakamoto, A. (2008). The effect of mobile-phone use on school children's friendship: An examination of causality with a panel study. Jpn. J. Pers., 16(3), 363-377.

Ames, C. (1992). Achievement goals, motivational climate, and motivational processes. In: Roberts, G. C. (Ed.) Motivation in Sport and Exercise. Human Kinetics, pp. 161-176.

Aoki, K., Fukuda, Y., Tani, K., Simoji, T., and Komatsua, Y. (2005). Study of the development of participant's IKIRU CHIKARA (Zest for Living) in waterwise program. Jpn. Outdoor Educ. J., 8(2), 59-70.

Barkoukis, V., Ntoumanis, N., and Thøgersen-Ntoumani, C. (2010). Developmental changes in achievement motivation and affect in physical education: Growth trajectories and demographic differences. Psychol. Sport and Exerc., 11(2): 83-90.

Chūō kyōiku shingikai (1996). 21seiki o tenbō shita wagakuni no kyōiku no arikata ni tsuite: Chūō kyōiku shingikai daiichiji tōshin. [Education in japan on the 21st century: Central council for education first report]. Japan Society of Educational Information 12(1): 17-54. (in Japanese)

Dweck, C. S. (1986). Motivational processes affecting learning. Am. Psychol., 41(10): 1040-1048.

Ferrer-Caja, E. and Weiss, M. (2000). Predictors of intrinsic motivation among adolescent students in physical education. Res. Q. Exerc. Sport, 71(3): 267-279.

Finkel, S. E. (1995). Causal analysis with panel data. Sage Publications: Thousand Oaks, CA. pp. 22-44.

Fujita, T. (2009). Relationship to goal orientation, motivation, and enjoyment in physical education. Bull. Educ. Res. Dev. Fac. Educ., Kagoshima Univ., 19: 51-60.

Fujita, T. and Sugihara, T. (2009). Prediction of exercise participation of university students based on intrinsic motivation in physical education while at high school. Jpn. J. Phys. Educ. Health and Sport Sci., 52(1): 19-28.

Furusawa, S., Toda, J., and Akatsuka, T. (2005). Aiming at the practice of environmental education in homemaking education at junior high school. Bull. Integrated Res. Center Educ. Pract., Utsunomiya Univ., 28: 483-492.

Fusamae, K., Okamoto, M., Miyake, Y., Fujimoto, T., Takada, M., Miyake, A., Fujiwara, H., and Esashi, Y. (2001). Ikiruchikara o hagukumu taiiku jugyō: Hitorihitori ga shutai-teki ni torikumu basukettobōru. [Physical education class to cultivate the zest for living: Independent basketball]. Chūtō kyōiku kenkyū kiyō/ Hiroshimadaigaku fuzoku Fukuyama chū kōtō gakkō, 41: 89-98. (in Japanese)

Gåstén, A., Jaakkola, T., Liukkonen, J., Watt, A., and Yli-Piipari, S. (2012). Prediction of enjoyment in school physical education. J. Sports Sci. and Med., 11(2): 260-269.

Hara, Y. and Matsuda, K. (2008). The study of teacher's influence for 'Motivational Climate' in physical education class. Bull. Tokyo Gakugei Univ. Arts and Sports Sci., 60: 143-151.

Halvari, H., Skjesol, K., and Bagøien, T. E. (2011). Motivational climates, achievement goals, and physical education outcomes: A longitudinal test of achievement goal theory. Scand. J. Educ. Res., 55(1): 79-104.

Hayashi, S., Abe, Y., Imamura, Y., Kume, S., Sakashita, K., Takajyou, R., Taguchi, T., Nakamura, K., Hirano, Y., Akita, M., and Saeki, A. (2016). Sūgaku o manabi tsudzukeru seito o sasaeru jugyō ni kansuru kenkyū: Mondai-dzukuri o daizai to shite. [Study on classes that support students who continue to study mathematics: Focusing on making questions]. Naruto Univ. Educ. forum for classroom res., 15: 81-86. (in Japanese)

Isogai, H., (2002). Dai 3-shō supōtsu senshu no mokuhyō settei to 
mokuhyō shikō-sei. [Chapter 3 Goal setting and goal orientation on athletes]. In: Tokunaga, K. (Ed.) Kenkō to kyōgi no supōtsu shinri. Tokyo: Fumaidō shuppan. pp. 133-134. (in Japanese)

Isogai, H., Ito, T., Nishida, T., Sasaki, B., Sugiyama, Y., and Shibukawa, T. (2008). Taiiku ni okeru dōkidzuke fun'iki sokutei shakudo sakusei no kokoromi. [Development of motivational climates scale in physical education]. Jpn. Society of Sport Psychol. 35th Annu. Conf. Proc., 194-195. (in Japanese)

Ito, T. (1998). 'Mokuhyō shikō-sei' to undō kōdō. ["Goal orientation" and exercise behavior]. J. Health Phys. Educ. Recreat., 48(5): 368-372. (in Japanese)

Ito, T. (2000). Dai 7-shō supōtsu ni okeru mokuhyō settei. [Chapter 7 Goal setting on sports]. In: Sugihara, T., Funakoshi, M., Kudo, T., and Nakagomi, S. (Eds.) Supōtsu shinri-gaku no sekai. Tokyo: Fukumura shuppan. pp. 95-107. (in Japanese)

Ito, T., Isogai, H., Nishida, T., Sasaki, B., Sugiyama, Y. and Shibukawa, T. (2008). A review of motivational climate research in physical education and sport. Mem. Fac. Educ. Shimane Univ., 42: 13-20.

Ito, T., Isogai, H., Nishida, T., Sasaki, B., Sugiyama, Y., and Shibukawa, T. (2013). Examination of a motivational model for physical education in schools: Relationships among perceived motivational climate, learning motive, and strategy use. Jpn. J. Phys. Educ. Health and Sport Sci., 58(2): 567-583.

Jaakkola, T., Washington, T., and Yli-Piipari, S. (2012). The association between motivation in school physical education and self-reported physical activity during finnish junior high school: A self-determination theory approach. Eur. Phys. Educ. Rev., 19(1): 127-141.

Kokkonen, J. A., Kokkonen, M. T., Telama, R. K., and Liukkonen, J. O. (2013). Teachers' behavior and pupils' achievement motivation as determinants of intended helping behavior in physical education. Scand. J. Educ. Res., 57(2): 199-216.

Miyata, M., Kitamura, H., Miyamoto, F. Fujisawa, K., and Watanabe, K. (2003). Test study for health care education at junior high school to acquire "IKIRU-CHIKARA" (life ability). Stud. Educ. Pract., 4: 115-124.

MEXT (2017). The course of study in junior high school. http:// www.mext.go.jp/component/a_menu/education/micro_detail/_ icsFiles/afieldfile/2017/06/21/1384661_5.pdf, (accessed 2017-08$01)$.

Moreno, J. A., Sicilia, A., Cervello, E., Huescar, E., and Dumitru, D. C. (2011). The relationship between goal orientations, motivational climate and self-reported discipline in physical education. J. Sports Sci. Med., 10: 119-129.

Moriyama, S. (2011). Taiiku-tekina shikō-ryoku o hagukumu hoken taiiku: 'Ikiruchikara' o sodateru budō no jugyō jissen. [Physical education class to cultivate the thinking skills: Judo lesson to cultivate the zest for living]. Shigadaigaku kyōiku gakubu fuzoku chūgakkō kenkyū kiyō, 53: 95-104.

Murohashi, H. (2003). Bunseki no yo-sa o hyōka suru: tekigōdo shihyō gairon. [Evaluate good analysis: Overview of fitness index]. In: Toyota, H. (Ed.) Kyōbunsan kōzō bunseki gimon-hen. Tokyo: Asakurashoten. pp. 122-125. (in Japanese)

Nakagawa, M., Okamura, T., Kurosawa, T., Araki, E., and Yoneyama, E. (2005). The effects of long-term and short-term camping on IKIRU CHIKARA (Zest for Living) of early adolescents. Jpn. Outdoor Educ. J., 8(2): 31-43.

Nakagawa, Y. and Arai, H. (2006). A study in the development of "ikiru chikara" (the zest for living) and its educational value in school sports club activities in the junior high schools. Bull. Couns. Guidance, 18: 55-66.

Nakamura, N., Kawaguchi, C., Suzuki, K., Koiso, T., Koyama, H., and Nishijima, N. (2001). A study on how a unit on dance cultivates students' ability to slove problems independently. Choreologia, 24: 63.

Nakasuga, T., Susaki, Y., Sakata, S., Kimura, A., and Sugiyama, Y. (2014). Influence of motivational climate and goal orientation on attitude toward physical education in junior high school students. Jan. J. Phys. Educ. Health and Sport Sci., 59(1): 315-327.

Nakasuga, T., Sakata, S., and Sugiyama, Y. (2015). The influence of motivational climates in physical education on outcome expectations of junior high school students. Jpn. J. Phys. Educ. Health and Sport Sci., 60(2): 759-772.

Nakasuga, T., Sakata, S., and Sugiyama, Y. (2017). The influence of motivational climates and goal orientations on satisfaction with physical education in senior high school students. Jpn. J. Phys. Educ. Health and Sport Sci., 62(1): 297-312.

Nicholls, J. G. (1983). Conceptions of ability and achievement motivationa: A theory and its Implications for education. In: Paris, S. G., Olson, G. M., and Stevenson, H. W. (Eds.) Learning and motivation in the classroom. Lawrence Erlbaum Associates, pp. 211-237.

Nishida, T., Ito, T., Sasaki, B., Isogai, H., Sugiyama, Y., and Shibukura, T. (2010). Factors that influence a "zest for living": from the perspectives of learning motivation, adaptation to stress, and psychosocial skills in physical education class. Nagoya J. Health, Phys. Fitness and Sports, 33 (1): 23-29.

Nishida, T. and Nishida, N. (1990). Developmental change of the achievement motivation for learning in physical education. Nagoya J. Health, Phys. Fitness and Sports, 13(1): 47-54.

Nishida, T. and Oga, S. (2008). A review of achievement goal theory in sport. Nagoya J. Health, Phys. Fitness and Sports, 31(1): 5-12.

Nishita, Y., Tange, C., Tomida, M., Ando, F., and Shimokata, H. (2014). The reciprocal relationship between intelligence and depressive symptoms among japanese elderly adults. Jpn. J. Dev. Psychol., 25(1): 76-86.

Nishijima, T., Suzuki, K., Koyama, H., Kawaguchi, C., and Komatsuzaki, S. (2000). Causal structure analysis on promotion process of initiative problem-solving ability in physical education program in junior high school. Jpn. J. Phys. Educ. Health and Sport Sci., 45(3): 347-359.

Ntoumanis, N. and Biddle, S. (1999). A review of motivational climate in physical activity. J. Sports Sci., 17: 643-665.

Okabayashi, H., Sugisawa, H., and Kishino, H. (1998). Otoshiyori no kenkō to hito to no fureai: Jūdan kenkyū no imi suru mono. [Elderly health and interaction with people: Meaning of longitudinal research]. In: Toyota, H. (Ed.) Kyoubunsankouzoubunseki jireihen-kouzouhouteishikimoderingu-. Tokyo: Kitaoujishyobo. pp. 83-90. (in Japanese)

Okamoto, M., Iwata, S., Higashi, Y., Fusamae, K., Fujimoto, T., Takada, M., Fujiwara, H., Aida, D., and Matsuoka, S. (2004). Physical education lessons to encourage a zest for living: Long jump to promote self-improvement. Hiroshimadaigaku gakubu fuzoku gakkō kyōdō kenkyū kikō kenkyū kiyō, 32: 265-274. (in Japanese)

Okazawa, Y., Kita, M., and Suwa, Y. (1996). Factorial structure of physical competence and its developmental tendency and sex difference. Jpn. J. Sport Educ. Stud., 16(2): 145-155.

Omi, R., Sakamoto, A., Ando, R., Akiyama, K., Kimura, F., Kashibuchi, M., Naito, M., Takahira, M., Sakamoto, K., Adachi, N., Suzuki, K., Kato, S., and Sakamoto, T. (2005). Causal relationships between the internet use and the skill to practically use information: A three-wave panel study of junior high school students. Jpn. J. Educ. Technol., 29(1): 11-21. 
Papaioannou, A., Bebetsos, E., Theodorakis, Y., Christodoulidis, T., and Kouli, O. (2006). Causal relationships of sport and exercise involvement with goal orientations, perceived competence and intrinsic motivation in physical education: a longitudinal study. J. Sports Sci., 24(4): 367-382.

Roberts, G. C. (1992). Motivation in sport and Exercise: Conceptual constraints and convergence. In: Roberts, G. C. (ed.) Motivation in Sport and Exercise. Human Kinetics, pp. 3-29.

Roberts, G. C. and Kristiansen, E. (2012). Goal setting to enhance motivation in sport. In: Roberts, G. C. and Treasure, D. C. (Eds.) Advances in Motivation in Sport and Exercise (3rd ed.). Human Kinetics, pp. 207-231.

Sakairi, Y. (2008). 'Ikiruchikara' no ikusei to taiiku. [The cultivation of "zest for living" and physical education]. Contemp. Sports Critique, 18: 82-88. (in Japanese)

Sasaki, B. (2013). Dai 9-shō josei kyōgi-sha no dōkidzuke. [Chapter 9 Motivation for female athletes]. In: Nishida, T. (Ed.) Supōtsumochibēshon. Tokyo: Taishūkanshoten. pp. 135-150. (in Japanese)

Sasaki, Y. (2005). A report on the development and the evaluation of thinking and judging in social studies. Ochanomizujoshidaigaku fuzoku chūgakkō kiyō, 34: 11-25. (in Japanese)

Shimamoto, K. and Ishii, M. (2010). Estimation of causal relationships between sport experience in athletic clubs and life skills acquisition. Jpn. J. Sport Psychol., 37(2): 89-99.

Sumiya, S. (2005). Participation in extracurricular activities and students' satisfaction with junior high school: A latent growth curve model. Jpn. J. Dev. Psychol., 16(1): 26-35.

Tachibana, N., Hirano, Y., and Sekine, A. (2013). The effect of the long-term camping on IKIRU CHIKARA (Zest for Living) of early adolescents. Jpn. Outdoor Educ. J., 6(2): 1-12.

Takahira, M. (2006). Kodomo no intānetto shiyō to shakai-teki fu tekiō no kankei: Paneru chōsa ni yoru inga kankei no kentō. [Relationship between Children's Internet Use and Social Maladjustment: Examination of causality by panel stady]. Hattatsu, 27(105): 18-25.

Takahira, M., Ando, R., and Sakamoto, A. (2006). Estimation of causal effects through longitudinal study: An example of internet use and aggression. Jpn. J. Pers., 15(1): 87-102.

Toyota, H., Maeda, T., and Yanai, H. (1992). Genin wo saguru tōkei-gaku kyōbunsan kōzō bunseki nyūmon. Tokyo: Koudansha. pp. 174-177. (in Japanese)

Uebuchi, S. (2003). A review of achievement goal theories: Their early formations and theoretical transitions. Jpn. Psychol. Rev., 46(4): 640-654.

Watanabe, Y. and Ueya, K. (2003). Physical education learning for developing abilities of living through physical education class of long distance running in junior high school. Bull. Fac. Educ. Hum. Sci., 5(2): 187-196.

Yamaguchi, Y. (2012). Gaidansu no jikan o riyō shita jugyōdzukuri: Gijutsu kateika ni okeru 'ikiruchikara' no ikusei o mezashita kyōzai kaihatsu. [Creating classes using guidance time: Development of teaching materials aiming to foster the "zest for living" in technology and home economics]. Bull. Grad. Sch. Teach. Train. Yamagata Univ., 3: 266-269.

Yoshitake, N. (2010). Role of daily positive experiences in life satisfaction in junior high school students: Events collection and examination of a relationship. Jpn. J. Educ. Psychol., 58(2): 140-150.

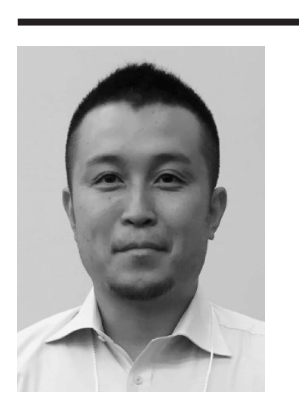

Name:
Takumi Nakasuga

Affiliation:

Graduate School of Education, Hyogo University of Teacher Education

\section{Address:}

942-1 Shimokume, Kato-shi, Hyogo 673-1494

Brief Biographical History:

2016-Present Lecture, Graduate School of Education, Hyogo University of Teacher Education

2014-2016 Lecture, Faculty of Health and Welfare Science, Fukuyama Heisei University

2013-2014 Research Associate, Osaka University of Health and Sport Sciences

Main Works:

- Nakasuga, T., Sakata, S., and Sugiyama, Y. (2017). The influence of motivational climates and goal orientations on satisfaction with physical education in senior high school students. Jpn. J. Phys. Educ. Health Sport Sci., 62: 297-312. (in Japanese with English abstract)

-Nakasuga, T., Sakata, S., and Sugiyama, Y. (2015). The influence of motivational climates in physical education on outcome expectations of junior high school students. Jpn. J. Phys. Educ. Health Sport Sci., 60: 759-772. (in Japanese with English abstract)

- Nakasuga, T., Susaki, Y., Sakata, S., Kimura, A., and Sugiyama, Y. (2014). Influence of motivational climate and goal orientation on attitude toward physical education in junior high school students. Jpn. J. Phys. Educ. Health Sport Sci., 59: 315-327. (in Japanese with English abstract)

Membership in Learned Societies:

-Japan Society of Physical Education, Health and Sport Sciences

- Japanese Society of Sport Psychology

- Japanese Association of Educational Psychology

- Japanese Society of Sport Education

- Japan Curriculum Research and Development Association

- Japan Society of Human Growth and Development

-Japan Society for the Pedagogy of Physical Education 